Mariya Tsebrenko, Victoriya Rezanova and Irina Tsebrenko

\title{
POLYPROPYLENE MICROFIBERS WITH A FILLER IN THE NANOSTATE
}

\author{
Kyiv National University of Technologies and Design \\ 2, N emirovich-Danchenko str., 01011 Kyiv, Ukraine \\ mfibers@ukr.net
}

Received: November 27, 2009 / Accepted: M ay 04, 2010

(C) Tsebrenko M., Rezanova V., Tsebrenko I., 2010

\begin{abstract}
The physico-chemical regularities of polypropylene microfibers obtained via processing polypropylene/copolyamide (PP/CPA) mixture melts filled with nanosilicas have been investigated. It has been shown that the chemical nature of silica functional groups affects the viscosity of PP/CPA melts. In spite of the solid state of additives the filling effect does not occur or reveals weakly. Silicas do not prevent the polypropylene fiber-forming in a copolyamide matrix but improve it. This is explained by the stabilizing action of silica additives on PP liquid streams. Nanofilled polypropylene microfibers with diameters 0.30 $0.15 \mathrm{~mm}$ have been obtained.
\end{abstract}

Keywords: polymer mixtures, viscosity, silica, microfibers, nanoadditives, interfacial tension.

\section{Introduction}

During last decade the nanostate is of great interest and is investigated intensively in the whole world. The decrease of substance sizes below some critical value sharply changes its properties and leads to the appearance of new unique phenomena [1-3]. Nanoobjects are characterized by a small size, complicated internal structure, dense packing, strong lateral interactions and very high ratio between the surface and the volume. Changing of nanomaterial characteristics is caused not only by the decrease of structural elements size, but also by the quantum-mechanical role of the interface. Varying of sizes and forms of nanostructures allows to obtain materials with new functional characteristics which are sharply different from the characteristics of ordinary materials. Polymer fibers gain the unique properties when their diameter decreases from micrometers to nanometers. Very high ratios between the surface and the volume, as well as the strength, are the most important nanofibers properties. The electroforming is the most wide-spread method of polymer nanofibers obtaining [4-6]. The electric field with a high voltage gradient is used to overcome the surface tension of polymer melts.

The second important direction in science and technology is development of composite polymer materials and composite fibers filled with additives in the nanostate. Carbon nanotubes, fullerens, clay, silica are used as nanofillers. The fibers with carbon nanotubes have unique properties: their strength is larger in 6 times than that of steel, but they are lighter in 100 times than steel [7]. Moreover, filling of the fibers with nanotubes (from 5 to 10 mas \%) ensures the high electrical conductivity (on the level of copper) and chemical stability. Introduction of clay particles into the fibers increases their electric conductivity, strength properties, ultraviolet tolerance, chemical stability and fire resistance. It is known that polypropylene fibers are difficult for colouring. This fact limits their using for production of consumer goods. Introduction of 15 mas \% of clay nanoparticles improves their colouring by various dyes. T. Malysheva and coworkers [7] investigated and produced the synthetic fibers filled with oxides of metals $\left(\mathrm{TiO}_{2}, \mathrm{Al}_{2} \mathrm{O}_{3}, \mathrm{ZnO}, \mathrm{MgO}\right)$. Obtained modified fibers are characterized by photocatalytic activity, ultraviolet tolerance, electric conductivity, antimicrobial action, mud repellence and photooxidative ability under various chemical and biological conditions [7].

The main fields of nanostructural materials usage are: electronics, computer technologies, chemistry, medicine, catalysis, space technologies, production of energy, biotechnologies, etc. Polymer nanofibers are used in cosmetics, military sphere, medicine, production of filters for purification of water, gaseous media and for filtration on the molecular level, as well as in other fields of industry (thermal and biochemical devices) [5, 6]. Literature analysis shows that in the XXI century nanotechnologies will find wide practical use in all fields of human activity. However the problems connected with technical difficulties and high cost price of final products remain very urgent. 
Using of polymer mixtures leads to the simple, accessible and effective way of polymer modification. Processing of polymer mixtures gives the possibility not only to combine the properties of two or more components in one product but also to obtain the unique effects $[8,9]$. The fundamental investigations in the area of physicochemistry of polymer mixture melts have been carried out in the laboratory of synthetic fibers of Kyiv National University of Technologies and Design [10, 11]. As a result of these investigations the scientific foundations of ultrathin synthetic fibers (microfibers) production have been developed. It has been shown that processing of the polymer mixture melts offers a new challenge of microfibers obtaining. The question is about the so called phenomenon of the specific fiber-formation, when during polymer mixture melt flowing through a forming opening the dispersed phase polymer (fiber-forming) forms a great number of microfibers strictly oriented in the flow direction under the influence of rheological forces within another (matrix) polymer. The formed microfibers have the diameter from several micrometers to tenth parts of micrometer. The unique structure of microfibers surface has been confirmed by the electron microscopy: along all surfaces each fiber is covered by superthin fibrils which branch off the main microfiber [10]. Such fibers do not exist in nature and they cannot be produced on the basis of traditional technologies.

It is known that a liquid stream (cylinder) is thermodynamically unstable $[12,13]$ due to an unfavorable ratio of the surface to the volume. A liquid stream with the ratio length/diameter ( $1 / \mathrm{d})$ more than 4.5 is a nonequilibrium system and its fracture is determined by local conditions of the flow, as well as by the rheological and interfacial properties of mixed fluids. In many papers it has been noted that the liquid cylinder surface becomes varicose before its fracture, so periodic thickening and thinning appear on it. On the basis of Rayleigh and Weber classical works [14, 15], Tomotika [16] analyzed the hydrodynamic stability of the liquid stream and explained Taylor's experimental results. According to the existing concepts, the appearance of the wave disturbances on the surface of the liquid cylinder is responsible for its fracture (Fig. 1).

The fracture causes the disturbance, and its amplitude increases with the maximum rate. The stream

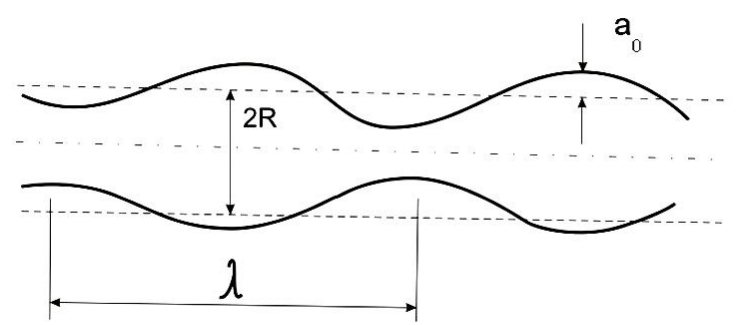

Fig. 1. Liquid cylinder undergoing capillary wave action is destroyed when the disturbance amplitude becomes equal to the stream radius. This phenomenon takes place during the time $t_{\text {life }}$, called the lifetime of the liquid cylinder, or the fracture time.

At first approximation, the lifetime of the liquid stream (time of break-up for droplets) is determined by the following expression:

$$
t_{l i f e}=R \eta / \gamma_{\alpha \beta}
$$

where $\eta$ is viscosity of fiber-forming polymer melt, $R$ is radius of the liquid stream, $\gamma^{\alpha \beta}$ is interfacial tension.

One can see from Eq. 1 that under other equal conditions liquid streams of smaller radius are stable at the decrease of $\gamma_{\alpha \beta}$, i.e. conditions for obtaining finer fibers are realized.

We have proposed the working hypothesis that introduction of filler nanoparticles prevents the growth of disturbance wave amplitude. Therefore the streams with considerably smaller diameters will be stable in the presence of the filler. It leads to obtaining fibers with nanosizes.

The aim of this work is investigation of the possibility to form microfibers with a nanostate filler.

\section{Experimental}

\subsection{Materials}

The mixtures of polypropylene/copolyamide (PP/CPA) with a component ratio of $30: 70$ mas \% were the objects of investigation. Isotactic polypropylene (PP) is a fiber-forming component (dispersed phase polymer). Copolyamide (CPA) - matrix polymer is a copolymer of caprolactam and hexamethylene - adipate in the ratio of $50: 50$. Both polymers are industrial polymers which are produced in large volumes. Besides PP is cheap and may be used in medical and food industries, it can be processed in melts without formation of harmful substances [17]. Copolyamide (CPA) has melting temperature $T_{m}$ which is close to PP melting temperature and is dissolved in ethanol. That is why it was chosen as a matrix polymer. The polymer ratio was taken according to investigations carried out early. Characteristics of PP and CPA are represented in Table 1.

Nanosilica A-300 (pilot plant of the Institute of Surface Chemistry, Kalush, Ukraine) and modified nanosilica MA-200 (MA-200 modified by hydrolyzed dimethyldichlorosilane) were used as solid additives in

Table 1

Characteristics of initial polymers

\begin{tabular}{|c|c|c|c|c|}
\hline $\begin{array}{c}\text { Poly- } \\
\text { mer }\end{array}$ & $T_{m}, \mathrm{~K}$ & $\begin{array}{c}\eta, \mathrm{Pa} \cdot \mathrm{s} \\
\text { at } T=463 \mathrm{~K} \\
\text { and } \tau=5.69 \cdot 10^{4} \mathrm{~Pa}\end{array}$ & $n$ & $B$ \\
\hline PP & 442 & 420 & 1.9 & 2.0 \\
\hline $\mathrm{CPA}$ & 443 & 640 & 1.2 & 1.4 \\
\hline
\end{tabular}


Characteristics of initial silicas

\begin{tabular}{|c|c|c|c|}
\hline No. & Characteristics & A-300 & MA-200 \\
\hline 1 & Average diameter of particles, $\mathrm{nm}$ & 7.0 & 12.0 \\
\hline 2 & Specific surface area by BET method $S_{B E T}, \mathrm{~m}^{2} / \mathrm{g}$ & $300 \pm 30$ & $200 \pm 25$ \\
\hline 3 & Large particles, mas $\%$ & 0.04 & 0.06 \\
\hline 4 & PH of water suspension & 3.6 & 3.6 \\
\hline 5 & Moisture, mas \% & 10.0 & 1.5 \\
\hline 6 & Silica $\left(\mathrm{SiO}_{2}\right)$ after heat treatment at $673 \mathrm{~K}$, mas \% & 99.9 & 99.9 \\
\hline 7 & Iron oxide $\left(\mathrm{Fe}_{2} \mathrm{O}_{3}\right)$, mas \% & 0.003 & 0.003 \\
\hline 8 & Aluminium oxide $\left(\mathrm{Al}_{2} \mathrm{O}_{3}\right)$, mas \% & 0.05 & 0.05 \\
\hline 9 & Titanium dioxide $\left(\mathrm{TiO}_{2}\right)$, mas $\%$ & 0.02 & 0.03 \\
\hline
\end{tabular}

fiber-forming PP at concentrations of $0.5 ; 1.0 ; 3.0$ and 5.0 mas $\%$ of the polypropylene mass. Characteristics of silicas are represented in Table 2. Before using the unmodified nanosilica A-300 was heated in a muffler at $673 \mathrm{~K}$ for $2 \mathrm{~h}$, and modified silica MA-200 was dried in an oven at $423 \mathrm{~K}$ for $2 \mathrm{~h}$.

\subsection{Methods}

Polymer mixtures were prepared using a screwdisc extruder of a combined type. The principal mixing part of this machine is a pair of discs: movable and stationary. Blending of polymers takes place due to shear and elongation stresses in the slit between discs. The viscous properties of the melts were investigated using capillary viscometry in the range of shear stresses (ô) $4.98 \cdot 10^{3}-5.69 \cdot 10^{4} \mathrm{~Pa}$, at the temperature of $463 \mathrm{~K}$. The regime of flow " $n$ " was determined using tangent of a tangent angle slope to the abscissa axis in a given point of the flow curve. The regime of flowing " $n$ " shows the deflection degree from Newtonian regime. The elasticity of the melts was estimated by the swelling " $B$ " of the mixtures extrudates undergoing to annealing by the special procedure [18] for complete relaxation of the accumulated highly elastic strains. The capability of a mixture melt being longitudinally deformed was estimated by the maximum possible spinneret stretching $F_{\max }$, which was determined as the ratio of maximum velocity of the stream being winded onto the bobbin to velocity of the melt outgoing from the die. The processes of structure-formation in the extrudates of the mixtures were investigated qualitatively and quantitatively by the methods of light and electron microscopy with the statistical analysis of all structure types (continuous and short fibers, particles, films) in the residue after the extraction of CPA from the extrudates. As a result the average diameters $(d)$ of fibers, distribution dispersion $\left(\sigma^{2}\right)$ and weight fraction of different PP structures were determined.

To study the fracture of microfibers, longitudinal sections of polymer mixtures extrudates (thickness of the section is $10-20 \mathrm{Mm}$ ) were placed on thermal chuckat of a microscope in an immersion medium at definite temperature, depending on the nature of the polymer, or at room temperature, increasing it gradually later on. Different stages of dispersed phase of polymer fiber fracture were photographed. As described in [19], we treated the microscope data in terms of Tomotika's theory [16]. In this case, we determined the wavelength $\lambda_{m}$ and the wave number $2 \pi R / \lambda$ of the destructive disturbance, the radius $R$ of the initial liquid cylinder (fiber), the radius $r_{d}$ of the drops resulting from the fracture, reduced value $r_{d}^{d} / R$ and the lifetime $t_{\text {life }}$ of a liquid cylinder. The initial experimental data were treated by the methods of mathematical statistics. The error in determining the values of $r_{d}$ and $\lambda_{m}$ was $\pm 3.5 \%$ with the confidence level of 0.95 .

To study regularities in the phase transitions of the polymer blends, thermograms of melting and crystallization were recorded using Q-1500D (Paulik, Paylik \& Erdey, MOM, Budapest) apparatus with TGDTA (thermogravimetry with differential thermal analysis), platinum crucibles for ground polymer samples $(190 \mathrm{mg}$ in weight) and $\mathrm{Al}_{2} \mathrm{O}_{3}$ powder as the standard. The thermograms of the melting were recorded at a heating rate $\beta=5 \mathrm{~K} / \mathrm{min}$ at $T=293-473 \mathrm{~K}$ and then the crystallization curves of the melts were recorded at cooling rate $\beta=1.5 \mathrm{~K} / \mathrm{min}$. Melting temperatures $\left(T_{m}\right)$, melting temperature range $\left(\Delta T_{m}\right)$, crystallization temperature $\left(T_{c}\right)$ and crystallization temperature range $\left(\Delta T_{c}\right)$ were determined using the thermograms. The average relative error was $\pm 2 \mathrm{~K}$. The crystallinity degree $(D C)$ was determined on the basis of the enthalpy of entirely crystalline polymer and melting enthalpy of the experimental sample. On the basis of TGA data the loss weigth $(\Delta m)$ was found.

A special procedure was developed for quantitative estimation of the structure-formation process in the flow of the polymer mixture melts. This procedure enables to evaluate and measure all types of structures which may develop in the extrudate of the polymer mixture with high accuracy and reliability. The procedure is as follows: under appropriate conditions an extrudate of $50 \mathrm{~mm}$ length was formed from PP/CPA mixture melt. The extrudate was placed in a packet of light filter paper and the matrix polymer was extracted by ethylalkohol (ethanol). From 
the PP residue the sample of $0.3 \mathrm{~mm}$ length was cut off. The sample was distributed (under the microscope) in an immersion liquid on a slide and a quantitative microscopic analysis was carried out. The data obtained were treated statistically, determining the average diameter $(d)$ of fibers, particles, sizes of films, distribution dispersion $\left(\sigma^{2}\right)$, numerical and weight percent of every type of structure.

The values of specific surface area $\left(S_{B E T}\right)$ of the filter materials were obtained from isotherm of moisture sorption-desorption at different relative humidity [20].

The efficiency of filter materials was determined using aerosol particles meter.

\section{Results and Discussion}

\subsection{Rheological Properties of $\mathrm{N}$ anofilled Polypropylene/ Copolyamide M ixture Melts}

The obtained results testify that a chemical nature of silica influences essentially the rheological properties of PP/CPA mixture melts. There is a principle difference of the dependence viscosity versus the content of additive for methylsilica and A-300 silica (Figs. 2 and 3). The viscosity of mixture melts containing the methylsilica is lower than $\eta$ of the initial PP/CPA mixture melt at all investigated shear stress (Fig. 2). The curves have the extremum at methylsilica content of 1 mas $\%$. At further increasing of additive content the viscosity grows but it is lower than $\eta$ of the initial mixture melts. The effect of filling with a solid filler develops in such a case. Introduction of A-300 silica causes the structurization of mixture melt owing to interactions of silica sylanol groups with each other and with functional groups of CPA macromolecules. As a result of both processes the hydrogen bonds are formed. The latter is a reason of viscosity increasing (Fig. 3). However under conditions of the mixture melt processing $\left(\tau=5.69 \cdot 10^{4} \mathrm{~Pa}\right.$ and more $)$ a small increasing of the melt viscosity occurs (Fig. 3). In our opinion a minor effect of the filler on PP/CPA

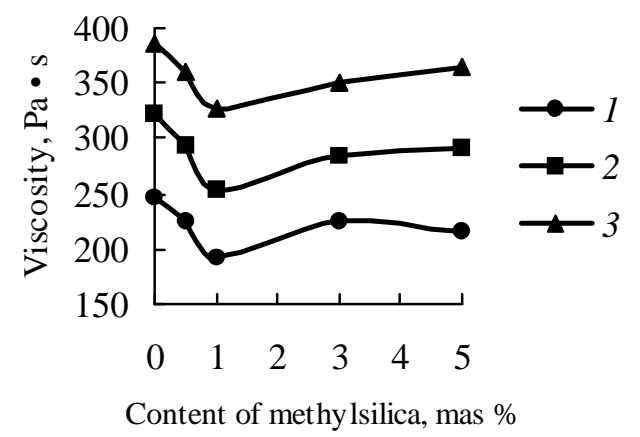

Fig. 2. Influence of methylsilica additives on viscosity of PP/CPA melt at $\tau \cdot 10^{-4} \mathrm{~Pa}: 5.69(1) ; 3.5$ (2); 2.3 (3)

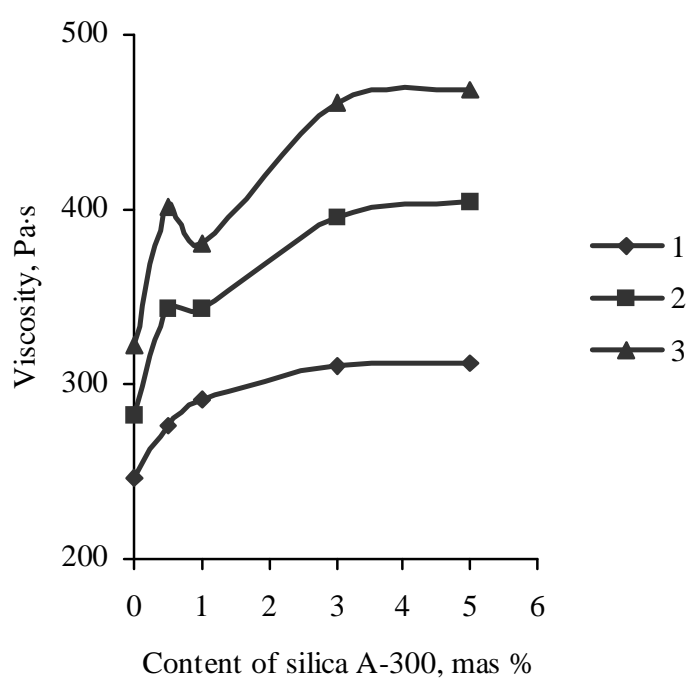

Fig. 3. Influence of silica A-300 additives on viscosity of PP/CPA melt at $\tau \cdot 10^{-4} \mathrm{~Pa}: 5.69$ (1); 4.2 (2); 3.5 (3)

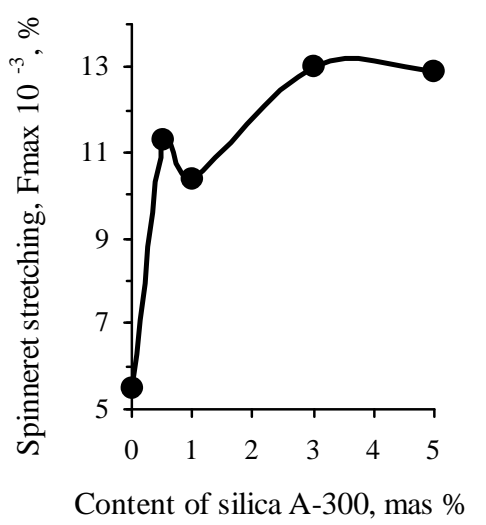

Fig. 4. Dependence of the maximum possible spinneret stretching versus silica A-300 content

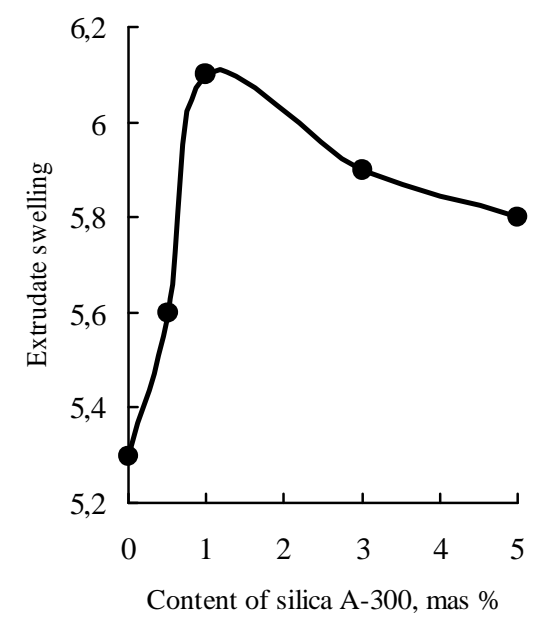

Fig. 5. Dependence of extrudate swelling versus silica A-300 content 
mixture melts viscosity is explained by a filler nanostate. Thus the traditional mechanisms for ordinary fillers are inapplicable in this case.

The dependence of the maximum possible spinneret stretching $\left(F_{\max }\right)$ upon silica content is expressed by the curve with maximum at 3 mas $\%$ of additive (Fig. 4). Thus the capability of a mixture melt of being longitudinally deformed increases. This is explained by forming the specific interactions between CPA macromolecules and hydroxyl groups of silica, which are situated on the surface of silica particles. As a result the strength of melt stream increases. The value of extrudate swelling " $B$ " is an indirect characteristic of the melt elasticity. Early it has been shown, that extrudate swelling correlates with the specific fiber-formation: the larger is the number of the formed microfibers in the flow of mixture melt and the thinner they are, the larger are the values of " $B$ ". Our experiments show that introduction of silicas into PP/CPA mixture leads to the increase of extrudate swelling. The curve $B=f$ (silica content) passes through the maximum when the additive content is 1 mas \% (Fig.5).

This is an indirect evidence of the pronounced fiberformation of polypropylene in the copolyamide matrix. The latter is confirmed by direct microscopic data.

\subsection{Peculiarities of Structure-Formation Processes in Filled PP/CPA Mixtures}

We were the first to establish that introduction of silica additives into polypropylene/copolyamide mixture improves PP fiber-forming at PP/CPA mixture flowing: PP microfibers in ternary extrudates $(2.0-2.6 \mu \mathrm{m})$ are much smaller than those in the binary mixture $(4.0 \mu \mathrm{m})$ (Table 3).

This fact is explained by the increase of breakdown time (lifetime) of a liquid stream in the presence of silica. For ternary mixture the mass part of PP microfibers increases to 97.4 against $55.4 \%$ for the binary mixture. The film content sharply decreases at introduction of silica. Thus the most important result obtained in our work is that the silica additives do not prevent PP fiber-forming in a CPA mass. This confirms our proposed working hypothesis about a stabilizing action of silica additives during the fiberforming process. The particles of silica are situated in PP microfibers which are the matrix for nanofiller. Thus the possibility of PP fibers modification appears.

The results of electron microscopy confirm the stabilizing action of silica additives on polypropylene liquid streams, which are formed during processing of PP/CPA mixture melts. There is a great number of varicose fibers and particles in the extrudate of binary PP/CPA mixture (Fig. 6a). They are the result of the thinnest polypropylene streams breakdown. Introduction of silica in amount of 1.0 mas \% stabilizes the liquid streams. As a result the varicosity has no place (Fig. 6b), the fibers of $0.3-0.15 \mu \mathrm{m}$ diameter appear.

All mentioned above sharply increases the specific surface of polypropylene microfibers and the filter materials based on them (Table 4).

If the specific surface of polypropylene microfibers from binary PP/CPA mixture is $84 \mathrm{~m}^{2} / \mathrm{g}$, then introduction of silica increases it to $352 \mathrm{~m}^{2} / \mathrm{g}$ (Table 4). That is why the filter materials produced from ternary PP/CPA/ silica mixtures are characterized by high efficiency at filtration of particles the size of which is less than one micron (Table 5). Thus silica additives not only favor polypropylene fiberforming in copolyamide matrix, but also improve it.

\subsection{Peculiarities of PP Liquid Streams Breakdown}

According to the classical Rayleigh-WeberTomotika theory [14-16], the disturbance amplitude $\alpha$ (Fig. 1) during stream breakdown grows exponentially with time $t$

Influence of silicas on structure-formation processes in PP/CPA mixtures

\begin{tabular}{|c|c|c|c|c|c|c|c|c|}
\hline \multirow{2}{*}{$\begin{array}{l}\text { Ratio of mixture } \\
\text { components, mas \% }\end{array}$} & \multicolumn{3}{|c|}{ Continuous fibers } & \multicolumn{2}{|c|}{ Short fibers } & \multicolumn{2}{|c|}{ Particles } & \multirow{2}{*}{$\begin{array}{l}\text { Films } \\
\text { mas \% }\end{array}$} \\
\hline & $d, \mu \mathrm{m}$ & mas \% & $\sigma^{2}$ & $d, \mu \mathrm{m}$ & mas \% & $d, \mu \mathrm{m}$ & mas \% & \\
\hline PP/CPA 30/70 & 4.0 & 55.40 & 1.4 & 2.2 & 1.35 & 2.5 & 0.05 & 43.2 \\
\hline PP/CPA/A-300 30/70/0.5 & 2.6 & 78.30 & 0.5 & 2.1 & 0.9 & 2.3 & 002 & 20.78 \\
\hline PP/CPA/A-300 30/70/1 & 2.0 & 91.0 & 0.3 & 1.8 & 0.04 & 2.0 & 0.01 & 8.95 \\
\hline PP/CPA/A-300 30/70/3 & 2.2 & 97.38 & 0.4 & 1.9 & 0.50 & 2.0 & 0.02 & 2.10 \\
\hline PP/CPA/A-300 30/70/5 & 2.4 & 78.58 & 0.4 & 2.1 & 1.0 & 2.1 & 0.03 & 20.39 \\
\hline $\begin{array}{l}\text { PP/CPA/methylsilica } \\
30 / 70 / 1.0\end{array}$ & 2.3 & 91.80 & 0.5 & 1.7 & 0.78 & 1.2 & 0.02 & 7.40 \\
\hline
\end{tabular}




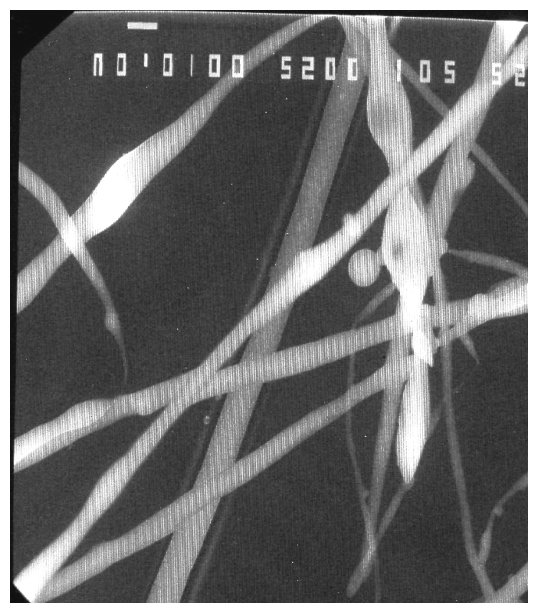

a)

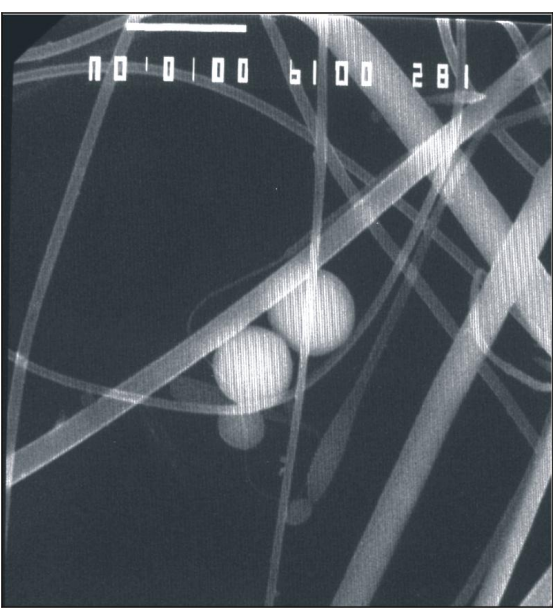

b)

Fig. 6. Electron microphotographs of ultrathin polypropylene fibers filled with A-300 silica. Silica content (mas \%): 0.0 (a) and 1.0 (b)

Table 4

Influence of A-300 silica additives on specific surface of PP microfibers

\begin{tabular}{|c|c|}
\hline Silica content, mas \% & Specific surface, $\mathrm{m}^{2} / \mathrm{g}$ \\
\hline 0 & 84 \\
\hline 0.5 & 197 \\
\hline 1.0 & 244 \\
\hline 3.0 & 307 \\
\hline 5.0 & 352 \\
\hline
\end{tabular}

Table 5

Efficiency of air filtration through filter material made from PP/CPA/A-300 mixture (30/70/1.0 mas \%)

\begin{tabular}{|c|c|c|c|}
\hline \multirow{2}{*}{ Particles size, $\mu \mathrm{m}$} & \multicolumn{2}{|c|}{ Number of particles in litre } & \multirow{2}{*}{ Efficiency, $\%$} \\
\cline { 2 - 4 } & in initial air & after the filter & 100 \\
\hline 1.0 & 19.311 & 0 & 100 \\
\hline 0.8 & 74.554 & 0 & 100 \\
\hline 0.6 & 256.806 & 0 & 100 \\
\hline 0.5 & 341.794 & 0 & 100 \\
\hline 0.4 & 356.169 & 0 & 99.999 \\
\hline 0.3 & 365.217 & 1 & \\
\hline
\end{tabular}

$$
\alpha=\alpha_{0} \exp (q t)
$$

where $a_{0}$ is the initial disturbance amplitude; $q$ is the instability factor, which is a complex function of the wave number $\mathrm{X}=2 \pi R / \lambda_{m}$ and the ratio between viscosity of the phases $K=\eta_{1} / \eta_{2}$

$$
q=\left(\frac{\gamma_{\alpha \beta}}{2 \eta_{1} R}\right) F(X, K)
$$

In logarithmic coordinates the $\alpha$ vs $t$ dependence is represented by a straight line

$$
\ln \alpha=\ln \alpha_{0}+q t
$$

The tangent of this line slope to the $\mathrm{X}$-ax is the instability factor $q$.
The analysis of kinetics of the PP microfibers breakdown in the CPA matrix shows that the experimental dependence of the disturbance amplitude $\alpha$ deviates from a straight line at the final stages of breakdown. Eq. (3) establishes the relationship between the instability factor of the stream and interfacial tension $\gamma_{\alpha \beta}$ which is the most important macroscopic characteristic of polymers mixture. The surface energy, structure, and length of interphase layer can be determined using $\gamma_{\alpha \beta}$ value. On the basis of above mentioned Chappelear [21] suggested a method for measuring the interfacial tension in a mixture of two polymers, one of which forms liquid streams (fibers) in another polymer. Experimental measurement of $\gamma_{\alpha \beta}$ in polymer mixtures (especially in melts) is very complicated. 
Parameters of PP microfibers breakdown in CPA matrix

\begin{tabular}{|l|c|c|c|c|c|c|c|c|c|}
\hline $\begin{array}{c}\text { Ratio of mixture } \\
\text { components, mas \% }\end{array}$ & $R, \mu \mathrm{m}$ & $\begin{array}{c}r_{d}, \\
\mu \mathrm{m}\end{array}$ & $\begin{array}{c}\lambda_{m}, \\
\mu \mathrm{m}\end{array}$ & $r_{d} / R$ & $\begin{array}{c}2 \pi R / \\
\lambda_{m}, \mathrm{~s}\end{array}$ & $\begin{array}{c}t_{\text {life }}, \\
\mathrm{s}\end{array}$ & $\begin{array}{c}\mathrm{t}_{\text {life }} / \mathrm{R}, \\
\mathrm{s} / \mu \mathrm{m}\end{array}$ & $q$ & $\begin{array}{c}\gamma_{\alpha \beta}, \\
\mathrm{mN} / \mathrm{m}\end{array}$ \\
\hline PP/CPA 30/70 & 2.16 & 3.79 & 15.56 & 1.75 & 0.87 & 84 & 38.9 & 0.0398 & 2.36 \\
\hline PP/CPA/A-300 30/70/1.0 & 1.37 & 2.54 & 11.53 & 1.84 & 0.75 & 55 & 49.4 & 0.0292 & 0.61 \\
\hline PP/CPA/methylsilica 30/70/1.0 & 1.52 & 2.83 & 13.17 & 1.87 & 0.72 & 75 & 62.4 & 0.0250 & 0.75 \\
\hline
\end{tabular}

Temperatures of phase transitions in PP/CPA/silica mixtures

\begin{tabular}{|c|c|c|c|c|c|c|c|c|}
\hline \multirow{3}{*}{$\begin{array}{l}\text { Ratio of components in } \\
\text { PP/CPA/A-300 mixtures, wt \% }\end{array}$} & \multirow{2}{*}{\multicolumn{2}{|c|}{ Melting }} & \multirow{3}{*}{$\begin{array}{l}\Delta m, \\
\text { wt } \%\end{array}$} & \multicolumn{5}{|c|}{ Crystallization } \\
\hline & & & & \multicolumn{2}{|c|}{ CPA } & \multicolumn{3}{|c|}{ PP } \\
\hline & $T_{m}, \mathrm{~K}$ & $\Delta T_{m} \mathrm{~K}$ & & $T_{c}, \mathrm{~K}$ & $\Delta T_{c}, \mathrm{~K}$ & $T_{c}, \mathrm{~K}$ & $\Delta T_{c}, \mathrm{~K}$ & $D C_{c} \%$ \\
\hline $100 / 0 / 0^{*}$ & 441 & 28 & 0 & - & - & 386 & 10.0 & 43.1 \\
\hline $0 / 100 / 0^{*}$ & 439 & 26 & 2.1 & 411 & 6.0 & - & - & - \\
\hline $30 / 70 / 0$ & 441 & 18 & 2.3 & 413 & 6.0 & 395 & 6.0 & 18.5 \\
\hline $30 / 70 / 0.5$ & 438 & 15 & 2.2 & 412 & 6.0 & $\begin{array}{l}395 \\
392 \\
381\end{array}$ & 3.0 & 38.5 \\
\hline $30 / 70 / 1.0$ & 442 & 14 & 1.1 & 415 & 4.0 & 398 & 4.0 & 26.6 \\
\hline $30 / 70 / 3.0$ & 442 & 15 & 1.5 & 413 & 4.0 & 395 & 4.0 & 24.9 \\
\hline $30 / 70 / 5.0$ & 443 & 21 & 1.2 & 412 & 4.0 & $\begin{array}{l}397 \\
393\end{array}$ & 4.0 & 32.5 \\
\hline
\end{tabular}

* after extrusion at screw-disc extruder

Therefore, application of the theory of destabilization of a liquid cylinder for determining $\gamma_{\alpha \beta}$ is of particular interest.

On the basis of experimental data concerning the kinetics of microfibers breakdown in the polymer mixtures, we have calculated the values of interfacial tension (Table 6).

It is obvious that obtained $\gamma_{\alpha \beta}$ values are low. This is typical for polymer mixtures [19] and explained by the presence of a transition layer at the interface of the components. Data from Table 6 show that introduction of silica additives essentially increases the lifetime of PP liquid cylinder (stream) and decreases the interfacial tension. Both these factors earnestly confirm the stabilizing effect of aerosil additives on PP liquid streams. It opens the way of obtaining thinner PP microfibers. Obtained data are in agreement with the results of electron microscopy (Fig. 6). Thus, experimental results confirm our working hypothesis about the stabilizing action of silica additives.

\subsection{Effect of Silica Additives on Phase Transitions in PP/ CPA Mixtures}

The morphology of the polymer mixture is substantially determined by components capability to crystallization. From Table 7 it is seen that PP has high melting and crystallization heats.
Copolyamide has an irregular chemical structure and its melting and crystallization heats are less than those for polypropylene. At melting the loss of PP mass has no place while for initial CPA $\Delta m$ is $2.1 \%$. This is explained by lowmolecular compounds forming during CPA melting followed by their evaporation. These lowmolecular compounds have the plasticizing action on CPA melt. The processes of PP and CPA melting in the mixtures proceed simultaneously. At crystallization CPA crystallizes the first and PP crystallizes on the solid surface (epitaxial crystallization). That is why some increase of PP crystallization temperature takes place (Table 7). The decrease of PP crystallization heat and $D C_{c}$ is explained by its disperse state in the mixtures. It is known [22] that the crystallization rate of the polymer in the mixture is determined by its degree of dispersion: the rate decreases with the size decrease of dispersed phase. It is connected with the changes in the transition layer which is formed between mixture components. The quantitative microscopic analysis shows that PP forms a great number of continuous microfibers in CPA mass. For ternary PP/CPA/silica mixtures the PP fiber-forming is improved and PP content in the transition layer increases. Two additional peaks appear on crystallization thermograms of $\mathrm{PP} / \mathrm{CPA} /$ silica mixtures (Table 7). For ternary mixtures the loss of CPA mass decreases. It is explained by the absorption of lowmolecular compounds on the surface of silica particles. 
One can see from Table 7 that narrowing of the temperature intervals of crystallization and melting processes has place for ternary mixtures. The degree of PP crystallinity in ternary mixtures also increases compared with that in the binary mixture. This result is stipulated by intensification of nucleation over silica particles and solid surface of CPA, which has already crystallized during the cooling process. Thus, introduction of high dispersive silicas into binary PP/CPA mixture is the effective method of the structure-formation regulation for the polymer dispersed phase during mixture processing.

\section{Conclusions}

For the first time the influence of filler (silica) in the nanostate on the flowing and structure-formation processes in polypropylene/copolyamide mixture melts has been studied. It has been shown that silica additives do not prevent polypropylene fiber-forming in the copolyamide matrix, but improve it. This fact is explained by the stabilizing action of silica additives on liquid streams of PP by suppression of the disturbance wave amplitude growth. All above-mentioned has ensured PP microfibers obtaining with an increased (in three-four times) specific surface. Nanosilica with grafted dimethylsilyl groups is the more effective additive for fiber formation than nonmodified nanosilica due to its stronger affinity to polypropylene.

It has been shown that the rheological properties of filled PP/CPA mixture melts are determined by the chemical nature of groups over silica particles surface.

The stabilizing action of silica additives has been confirmed by data about the increasing life time of PP liquid streams in CPA matrix and essential decreasing interfacial tension. Thus the proposed by us working hypothesis about the stabilizing action of silica additives has been confirmed.

Addition of nanosilicas to the binary PP/CPA mixture changes phase transitions of polymers. Nanoparticles of silicas can be crystallization centers resulting in the increase of crystallinity degree.

\section{Acknowledgements}

These investigations have been carried out in accordance with the grant of State Fund of Fundamental Investigations of Ukrainian Ministry of Education and Science F25.4/177 "Micro- and macrorheological processes in nanofilled polymer mixtures" and the theme "Physico-chemical regularities of polypropylene microfibers modification by additives of nanosized silicas" was sponsored by the state budget.

\section{References}

[1] Sreekala M., Lehmann B., Friedrich K. and Rony M.: Int. J. Polym. Mater., 2006, 8, 577.

[2] Lei Li, Bellan L., Craighead H. and Frey M.: Polymer, 2006, 17, 628 .

[3] Roko M., Wilyms R. and Alivshatos P.: Nanotechnologii v Bligajshie Desyatiletiya. Prognoz Napravlenij Issledovanij. Mir, Moskwa 2002.

[4] Zheng-Ming H., Kotaki M. and Ramakrishna S.: Innovation, 2005, 5, 5.

[5] Bognitzki M, Frese T., Steinhart M. et al. J.: Polym. Eng. Sci., 2001, 41, 982.

[6] Doshi J. and Reneker D.: J. Electrostatics, 1995, 35, 151.

[7] Malyshewa T.: Obzor Rynka, 2001, 471, 194.

[8] Kulichihin V., Plotnikova E., Terezin A., et al.: Vysokomol. Soed., 2000, A 42, 2532.

[9] Tsebrenko M., Yudin A., Ablazova T. and Vinogradov G.: Polymer, 1976, 17, 831.

[10] Tsebrenko M.: Ultratonkie Sinteticheskie Volokna. Khimia, Moskwa 1991.

[11] Tsebrenko M.: Int. J. Polym. Mater., 1983, 10, 83.

[12] Sercov A., Egorova P.: Teoriya Obrazovania Khimicheskih Volokon. Khimia, Moskwa 1975.

[13] Han C. and Funatsu K.: J. Rheol., 1978, 22, 571.

[14] Rayleigh L.: Philos. Mag., 1982, 34, 145.

[15] Weber C. and Angew Z.: Math., 1931, 11, 113.

[16] Tomotika S.: Proc. Roy. Soc. (London), 1936, A153, 302.

[17] Yambrih M., Budzak D., Yambrih P. et al.: Preprints of Int. Conf. Chem. Fibers, 2000, 1, 2.

[18] Utracki L., Bakerdjiane Z. and Kamal M.: J. Appl. Polym. Sci., 1975, 19, 481.

[19] Tsebrenko M., Danilova G. and Malkin A.: J. NonNewtonian Fluid Mech., 1989, 31, 1.

[20] Lutsik P., Malkin E. and Abarji I.: Teplo- i Masoperedacha pri Obrabotke Tekstilya. Naukova dumka, Kyiv 1993.

[21] Chappeler D.: Amer. Chem. Soc. Polym. Prepr., 1964, 5363. [22] Nikiforova A., Chalih A., Avdeev N. and Zelener Y.: Plastmasy, 1981, 4, 36.

\section{ПОЛІПРОПІЛЕНОВІ МІКРОВОЛОКНА З НАПОВНЮВАЧЕМ В НАНОСТАНІ}

Анотація. Досліджені фізико-хімічні закономірності одержання поліпропіленових мікроволокон шляхом перероблення розплавів сумішей поліпропілен/співполіамід (ПП/СПА), наповнених нанокремнеземами. Показано, що хімічна природа функцій них груп кремнеземів впливає на в'язкість розплавів ПП/СПА. Незважаючи на твердий стан добавки, ефект наповнення не має місия або проявляється слабо. Кремнеземи не перешкоджають волокноутворенню поліпропілену, а покрашують його. Останнє пояснюється стабілізуючою дією нанодобавки на рідкі струмені ПП. Одержані поліпропіленові мікроволокна з діаметрами 0,30-0,15 мкм, наповнені нанокремнеземами.

Ключові слова: суміші полімерів, в'язкість, мікроволокна, кремнезем, нанодобавки, міжфазний натяг. 